\title{
High-Efficiency Preparation of 2,5-Diformylfuran with a Keto-ABNO Catalyst Under Mild Conditions
}

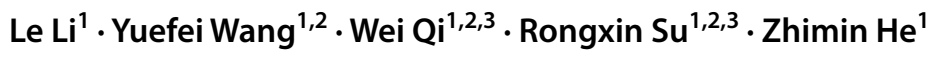

Received: 30 March 2018 / Revised: 22 April 2018 / Accepted: 3 May 2018 / Published online: 26 May 2018

(c) The Author(s) 2018

\begin{abstract}
In this paper, we report a new catalytic system for realizing the rapid and efficient oxidation of 5-hydroxymethylfurfural (HMF). First, we used 9-azabicyclo [3.3.1]nonan-3-one-N-oxyl (keto-ABNO) as a catalyst for the aerobic oxidation of 5-hydroxymethylfurfural (HMF) to 2,5-diformylfuran (DFF) in acetic acid. Then, we systematically studied the important reaction parameters, including the solvent, co-catalyst, and temperature. The results demonstrate that the acidic solvent used is crucial for the efficient oxidation of HMF to DFF. Under optimal conditions, we achieved a $93.4 \%$ yield of DFF within half an hour at room temperature. We also proposed the possible mechanism for this system.
\end{abstract}

Keywords Biomass · 5-Hydroxymethylfurfural · 2,5-Diformylfuran · 9-Azabicyclo[3.3.1] nonan-3-one-N-oxyl · Homogeneous catalysis

\section{Introduction}

With the current shortage of fossil fuels and rapid economic development, it is imperative to develop renewable resources. Biomass with plentiful, cheap, green, and renewable characteristics is attracting particular attention. In recent years, researchers have focused on the cost-effective conversion of biomass into high-value chemicals, biofuels, and biomaterials [1]. Scheme 1 illustrates the conversion of biomass into valuable chemicals, which involves the hydrolysis of polysaccharides to monosaccharides, and the dehydration of monosaccharides to furan compounds, such as 5-hydroxymethylfurfural (HMF). Subsequently, 2,5-diformylfuran (DFF), 5-hydroxymethylfuran-2-carboxylic acid (HMFCA), 5-formyl-2-carboxylic acid (FFCA), 2,5-furandicarboxylicacid (FDCA), 2,5-dimethylcarboxylate (FDMC), and 2,5-dimethylfuran (DMF) can be obtained from HMF

Wei Qi

qiwei@tju.edu.cn

1 State Key Laboratory of Chemical Engineering, School of Chemical Engineering and Technology, Tianjin University, Tianjin 300350, China

2 Tianjin Key Laboratory of Membrane Science and Desalination Technology, Tianjin 300350, China

3 Collaborative Innovation Center of Chemical Science and Engineering (Tianjin), Tianjin 300350, China
[2-8]. Of these, DFF is one of the most valuable furan derivatives (ca. \$30-65 per $100 \mathrm{mg}$ ) and shows great promise for the synthesis of pharmaceuticals, antifungal agents, and Schiff's bases [9-11]. Moreover, with the two symmetrical aldehyde groups, DFF can also be used as a macrocyclic ligand and monomer in the construction of multi-functional materials [12-14]. Therefore, the synthesis of DFF from biomass has attracted a lot of attention in recent years.

Fructose is a representative sugar molecule from biomass, which can be converted into DFF via a one-pot reaction. As early as 2003, Gary et al. reported a catalytic system of Amberlyst-15 and polyaniline-VO (acac) for the one-pot conversion of fructose into DFF with a yield of $42.1 \%$ [15]. Recently, Yang et al. [16] developed bifunctional catalyst Ce-Mo composite oxides to catalyze the transformation of fructose into DFF, with a yield of $80 \%$. However, the transformation of fructose to DFF involves a complex reaction system comprising both dehydration and oxidation reactions and the yield of DFF is always poor. The aerobic oxidation of HMF to DFF is more simple and efficient. In general, there are two strategies for the aerobic oxidation of HMF to DFF: heterogeneous catalysis and homogeneous catalysis. For heterogeneous catalysis, VO [17, 18], Co [19, 20], $\mathrm{Mn}[21]$, and $\mathrm{Ru}[22,23]$ show promising catalytic activity. However, heterogeneous catalysis has some obvious shortcomings, i.e., high temperature and a long reaction period, which are not conducive to industrial-scale production. 


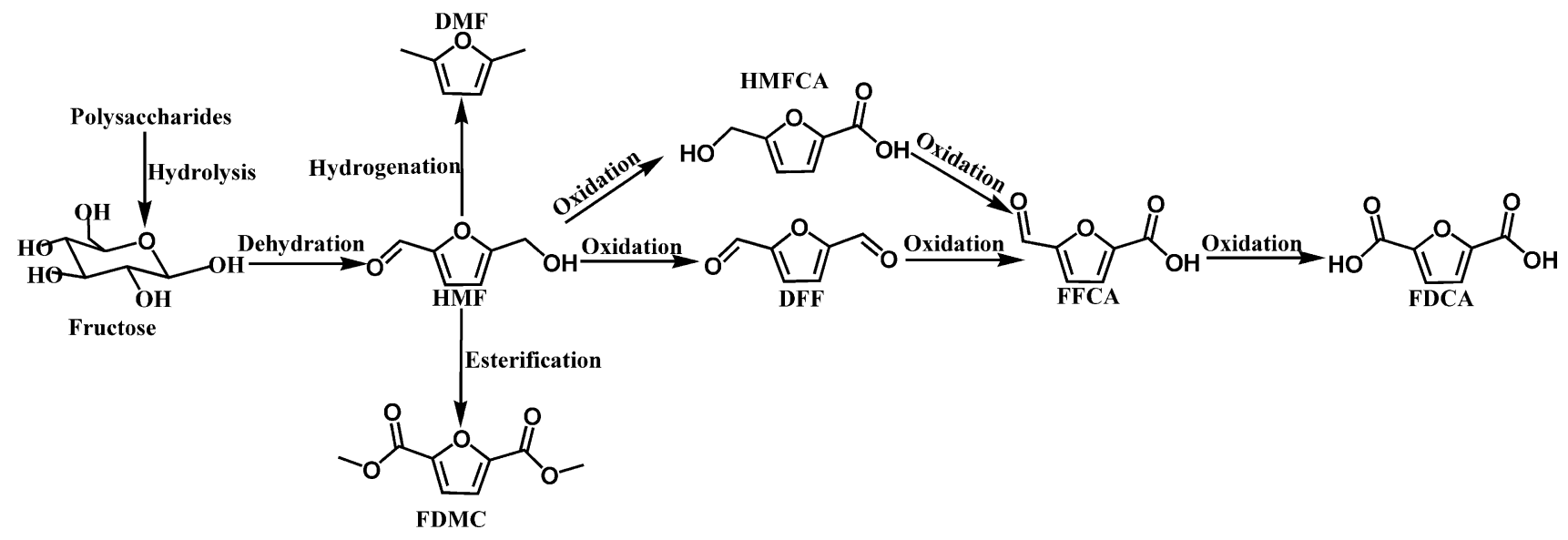

Scheme 1 Conversion process of biomass into high-value chemicals

Homogeneous catalysis, in contrast, reacts under milder conditions. A well-known example is the TEMPO catalytic system, which is well reported in the studies. For example, Fang et al. [24] developed a TEMPO/Fe catalytic system for the selective oxidation of HMF to DFF in air at room temperature. Mittal et al. [25] developed a TEMPO/BAIB/ $\mathrm{CH}_{3} \mathrm{COOH}$ catalytic system for the selective oxidation of HMF to DFF with a yield of $66 \%$ at $30{ }^{\circ} \mathrm{C}$ within $45 \mathrm{~min}$.

Recently, Lauber and Stahl [26] described the catalytic oxidation of a wide range of secondary alcohols using readily available ABNO-based catalysts in combination with $\mathrm{HNO}_{3}$ and $\mathrm{NaNO}_{2}$. The authors reported that both 9-azabicyclo[3.3.1]nonane-N-oxyl (ABNO) and 9-azabicyclo[3.3.1] nonan-3-one-N-oxyl (keto-ABNO) exhibited remarkable catalytic efficiencies. Considering that HMF contains an alcohol hydroxyl, which can be considered to be a primary alcohol, we speculated that keto-ABNO might be able to catalyze the oxidation of HMF to DFF with a good yield.

In this study, we investigated the catalytic ability of keto-ABNO for the oxidation reaction of HMF to DFF and systematically studied the effects of solvents, co-catalysts, amounts of catalyst and co-catalyst, atmosphere, temperature, and reaction time. We found that the acidic solvent used is crucial for the efficient oxidation of HMF. With ketoABNO serving as the catalyst and $\mathrm{NaNO}_{2}$ as the co-catalyst, we achieved a DFF yield of $93.4 \%$ within half an hour at room temperature.

\section{Experiments}

\section{Materials}

We purchased $\mathrm{Zn}\left(\mathrm{NO}_{3}\right)_{2} \cdot 4 \mathrm{H}_{2} \mathrm{O}, \mathrm{Na}_{2} \mathrm{CO}_{3}, \mathrm{Na}_{2} \mathrm{SO}_{4}, \mathrm{NaCl}$, $\mathrm{Na}_{2} \mathrm{SO}_{3}, \mathrm{Fe}\left(\mathrm{NO}_{3}\right)_{3} \cdot 9 \mathrm{H}_{2} \mathrm{O}, \mathrm{Cu}\left(\mathrm{NO}_{3}\right)_{2}$, and $\mathrm{NaNO}_{2}$ from Tianjin Guangfu Chemical Reagent Co. Ltd. (Tianjin, China); dimethyl sulfoxide, dimethylformamide, dichloromethane, acetonitrile, tetrahydrofuran, ethyl acetate, acetic acid, sodium nitrite, and 5-hydroxymethyl-2-furfural from Aladdin Reagent Co. Ltd. (Shanghai, China); keto-ABNO from Beijing J \& K Chemical Co., Ltd. (Beijing, China); and 2,5-diformylfuran from TCI Development Co. Ltd. (Shanghai, China).

\section{General Procedure for the Aerobic Oxidation of HMF}

We performed the oxidation of HMF in a glass tube equipped with a total reflux condenser and magnetic stirrer and introduced molecular oxygen through an airway. First, we charged the glass tube with HMF ( $63 \mathrm{mg}, 0.5 \mathrm{mmol}$ ), and then we added the keto-ABNO ( $2 \mathrm{mg}), \mathrm{NaNO}_{2}(3.4 \mathrm{mg}$, $0.025 \mathrm{mmol}$ ), and $4 \mathrm{~mL}$ of acetic acid. We heated the reactor at room temperature with an $\mathrm{O}_{2}$ flow rate of $10 \mathrm{~mL} /$ min. Lastly, we analyzed the furan compounds by gas chromatography.

\section{Analytic Methods}

We analyzed the furan compounds with an Agilent gas chromatograph equipped with an HP-5 column $(30 \mathrm{~m} \times 320 \mu \mathrm{m} \times 0.25 \mu \mathrm{m})$. We calculated the HMF and DFF contents in the samples using an external standard calibration curve that had been constructed based on the pure compounds. The retention times of HMF and DFF were 2.7 and $5.4 \mathrm{~min}$, respectively.

HMF conversion $(\%)=$

Moles of HMF added - Moles of unreacted HMF

Moles of HMF added

$$
\times 100 \%
$$

DFF yield $(\%)=\frac{\text { Moles of DFF }}{\text { Moles of HMF added }} \times 100 \%$ 
DFF selectivity $(\%)=\frac{\text { DFF yield }}{\text { HMF conversion }} \times 100 \%$

\section{Results and Discussion}

\section{Effect of Solvents on the Oxidation of HMF to DFF}

We used keto-ABNO and $\mathrm{NaNO}_{2}$ to catalyze the oxidation of HMF to DFF (Table 1). In this system, keto-ABNO serves as the catalyst and $\mathrm{NaNO}_{2}$ as the co-catalyst. As the solvent polarity, dielectric constant, steric hindrance, and acid-base properties play decisive roles in reactions [27], we first investigated the influence of various solvents on the catalytic reaction. Table 1 shows the results, in which we can see that reaction in acetic acid proved to be the best, with a full conversion of $\mathrm{HMF}$ and $81.1 \%$ selectivity of DFF through the catalysis of keto-ABNO and $\mathrm{NaNO}_{2}$ for $2 \mathrm{~h}$ at $40{ }^{\circ} \mathrm{C}$. When using other solvents, i.e., acetonitrile, dimethylsulfoxide, dimethylformamide, tetrahydrofuran, and ethyl acetate, we detected almost no DFF product. In studies, acetonitrile has been frequently used when ABNO is the catalyst. However, in our catalytic system, the yield of DFF in acetonitrile was very low. This distinct difference might be attributed to the use of a different co-catalyst from that had been used in previous work. In the keto-ABNO and $\mathrm{NaNO}_{2}$ catalytic system, the $\mathrm{NO}_{x}$ sources serve as an intermediate of the electron transfer, which is crucial for the efficient catalysis of HMF. In the study of Wang et al. [28], $\mathrm{NO}_{x}$ was generated by $\mathrm{Fe}^{3+}$ and $\mathrm{NO}_{3}{ }^{-}$. However, in our catalytic system, $\mathrm{NO}_{x}$ sources are generated from $\mathrm{NO}_{2}^{-}$and $\mathrm{H}^{+}$. In the absence of $\mathrm{H}^{+}$, no $\mathrm{NO}_{x}$ would form and thus the yield of DFF would be negligible.

Table 1 Aerobic oxidation of HMF to DFF in various solvents

\begin{tabular}{lllll}
\hline & & & \\
\hline Entry & Solvent & DFF yield (\%) & DFF \\
selectiv- \\
\end{tabular}

Reaction conditions: HMF (65 mg, $0.5 \mathrm{mmol}), \mathrm{NaNO}_{2}(3.5 \mathrm{mg}$, $0.025 \mathrm{mmol})$, keto-ABNO $(2 \mathrm{mg})$, solvent $(4 \mathrm{~mL}), \mathrm{O}_{2}(10 \mathrm{~mL} / \mathrm{min})$, $40{ }^{\circ} \mathrm{C}, 2 \mathrm{~h}$
This result indicates that the acidic solvent used is of utmost importance in achieving high efficiency and high selectivity in the oxidation of HMF to DFF.

\section{Effects of Co-catalysts on the Oxidation of HMF to DFF}

Based on the above results, a good yield of DFF can be achieved via the co-catalysis of $\mathrm{NaNO}_{2}$. To gain further insights into this catalytic system, we investigated the influence of other commercial sodium and nitrate salts as cocatalysts on the oxidation of HMF to DFF, the results of which are summarized in Table 2. As we can see in the table, none of the sodium salts worked well (Table 2, entries 1, $2,3,4)$. The conversions of HMF were less than $30 \%$ and DFF was almost undetectable. In contrast, the nitrate salts (Table 2, entries 5, 6, 8) yielded better than $90 \%$ conversions of HMF and the DFF yields were also good. It indicates that nitrate salts exhibit a significant co-catalytic effect with ketoABNO. Of the three, $\mathrm{NaNO}_{2}$ and $\mathrm{Cu}\left(\mathrm{NO}_{3}\right)_{2}$ generated the best results with full conversions of $\mathrm{HMF}$ and a DFF yield of $80 \%$ after reaction for $2 \mathrm{~h}$ in acetic acid at $40^{\circ} \mathrm{C}$. Selectivity to DFF was lower when using $\mathrm{Fe}\left(\mathrm{NO}_{3}\right)_{3}$ as the co-catalyst. It is easy to understand that $\mathrm{Fe}^{3+}$ exhibited a better oxidation ability than $\mathrm{Cu}^{2+}$, which might lead to the excessive oxidation of the hydroxyl group. The HMF would overreact with other high-value furan compounds. Moreover, when we used $\mathrm{Zn}\left(\mathrm{NO}_{3}\right)_{2}$ as the co-catalyst, no DFF was detected, which may be attributed to the inactivation of $\mathrm{Zn}^{2+}$. However, the $\mathrm{Fe}^{3+}$ and $\mathrm{Cu}^{2+}$ could be easily reduced and reoxidized between different valence states [28, 29]. In the catalytic reaction process, $\mathrm{Fe}^{3+}$ and $\mathrm{Cu}^{2+}$ are coupled with the catalyst and then react with the alcohol to form another intermediate by the release of $\mathrm{H}^{+}$. With the $\beta-\mathrm{H}$ and reductive eliminations, the alcohol is oxidized to aldehyde as $\mathrm{Fe}^{2+}$ and $\mathrm{Cu}^{+}$ are released. Then, the $\mathrm{Fe}^{2+}$ and $\mathrm{Cu}^{+}$are reoxidized to $\mathrm{Fe}^{3+}$ and $\mathrm{Cu}^{2+}$ by $\mathrm{NO}_{x}$. Based on these results, we conclude that

Table 2 Aerobic oxidation of HMF to DFF with different co-catalysts

\begin{tabular}{lllll}
\hline No. & Co-catalyst & $\begin{array}{l}\text { HMF conver- } \\
\text { sion (\%) }\end{array}$ & DFF yield (\%) & $\begin{array}{l}\text { DFF } \\
\text { selectiv- } \\
\text { ity (\%) }\end{array}$ \\
\hline 1 & $\mathrm{Na}_{2} \mathrm{CO}_{3}$ & 26.1 & $<1$ & $<1$ \\
2 & $\mathrm{Na}_{2} \mathrm{SO}_{4}$ & 25.1 & $<1$ & $<1$ \\
3 & $\mathrm{NaCl}_{4}$ & 26.5 & $<1$ & $<1$ \\
4 & $\mathrm{Na}_{2} \mathrm{SO}_{3}$ & 25.6 & 1.7 & 6.71 \\
5 & $\mathrm{Fe}\left(\mathrm{NO}_{3}\right)_{3}$ & 90.5 & 53.3 & 58.9 \\
6 & $\mathrm{Cu}\left(\mathrm{NO}_{3}\right)_{2}$ & 100.0 & 80.1 & 80.1 \\
7 & $\left.\mathrm{Zn}_{(} \mathrm{NO}_{3}\right)_{2}$ & 28.3 & $<1$ & $<1$ \\
8 & $\mathrm{NaNO}_{2}$ & 100.0 & 81.1 & 81.1 \\
\hline
\end{tabular}

Reaction conditions: HMF (65 mg, $0.5 \mathrm{mmol})$, co-catalyst $(3.4 \mathrm{mg}$ ), keto-ABNO (2 mg), acetic acid $(4 \mathrm{~mL}), \mathrm{O}_{2}(10 \mathrm{~mL} / \mathrm{min}), 40{ }^{\circ} \mathrm{C}, 2 \mathrm{~h}$ 
two conditions must be satisfied for an efficient co-catalyst. First, it should contain a lively base metal element. Second, the metal cations should be coupled with a catalyst. On this basis, $\mathrm{NaNO}_{2}, \mathrm{Cu}\left(\mathrm{NO}_{3}\right)_{2}$, and $\mathrm{Fe}\left(\mathrm{NO}_{3}\right)_{3}$ promote the efficient oxidation of HMF to DFF.

\section{Effect of Atmosphere on the Oxidation of HMF to DFF}

Compared to other oxidants, oxygen is inexpensive, green, and can be reused in liquid-phase reactions, so it has advantages in industrial fields. As such, in our experiment, oxygen was used as the oxidant. To investigate the effect of oxygen on the catalytic reactions, experiments were conducted under different atmospheres at $40{ }^{\circ} \mathrm{C}$, the results of which are summarized in Fig. 1. In oxygen atmosphere, we achieved the highest DFF yield of $81.1 \%$ with a full conversion of HMF. In an open-air atmosphere, the DFF yield dropped to $78.1 \%$. Exceeding our expectations, when the reaction was conducted in an inert nitrogen atmosphere, we realized an HMF conversion of $28.6 \%$ with a DFF selectivity of $41.0 \%$. In this situation, $\mathrm{NaNO}_{2}$ might act as the oxidant. In weak acid solvents, $\mathrm{NaNO}_{2}$ decomposes into $\mathrm{NO}_{2}$ and $\mathrm{NO}$ (Scheme 2). In an oxygen atmosphere, the reduced nitric oxide is reoxidized to nitrogen dioxide, leading to the continuous conversion of HMF. However, in a nitrogen atmosphere, the intermediate of $\mathrm{NO}_{2}$ serves as the oxidant for HMF and the conversion of HMF mainly depends on the amount of sodium nitrite used.

\section{Effect of the Amounts of Keto-ABNO and $\mathrm{NaNO}_{2}$ on the Oxidation of HMF to DFF}

It is known that the dosage of the catalyst will have a significant influence on a reaction. An insufficient amount of catalyst will lead to low catalytic efficiency, which is mainly manifested as a low conversion rate. However, an excessive

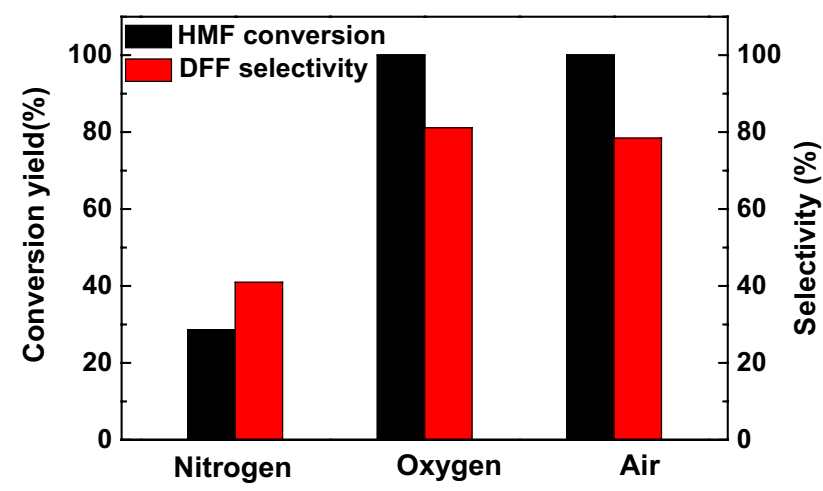

Fig. 1 Effects of atmosphere on keto-ABNO-catalyzed oxidation of HMF to DFF (reaction conditions: $\mathrm{HMF}$ ( $65 \mathrm{mg}, 0.5 \mathrm{mmol}$ ), $\mathrm{NaNO}_{2}$ (3.5 mg, $0.025 \mathrm{mmol})$, keto-ABNO $(2 \mathrm{mg})$, acetic acid $(4 \mathrm{~mL}), 40{ }^{\circ} \mathrm{C}$, $2 \mathrm{~h})$

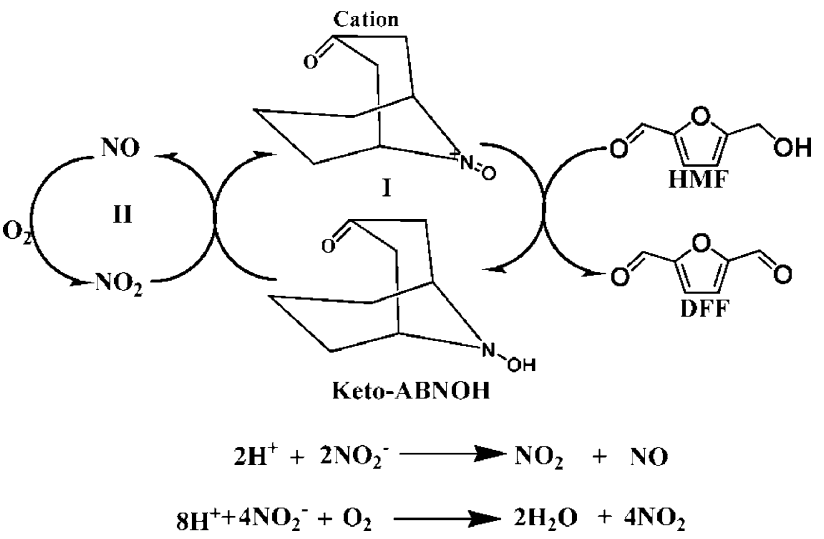

Scheme 2 Proposed mechanism for the keto-ABNO/NaNO${ }_{2}$-catalyzed oxidation of HMF to DFF

amount of a catalyst leads to an excessive reaction and increases production costs. We investigated the influence of the amounts of catalyst and co-catalyst on the oxidation of HMF to DFF, and the results are shown in Table 3. We found both keto-ABNO and $\mathrm{NaNO}_{2}$ to play crucial roles in the conversion of HMF to DFF. An experiment was also conducted without using keto-ABNO and $\mathrm{NaNO}_{2}$, for which no DFF could be detected (Table 3, entry 1). In the absence of keto-ABNO, only a HMF conversion of $69.4 \%$ was achieved, and no DFF could be detected (Table 3 , entry 2 ). In the presence of keto-ABNO without $\mathrm{NaNO}_{2}$, a full conversion of HMF was achieved, but the selectivity to DFF was relatively low (Table 3, entry 6). These results indicate that the highly selective oxidation of HMF to DFF requires a synergic catalytic effect between keto-ABNO and the co-catalyst $\mathrm{NaNO}_{2}$. Moreover, the insufficient use of keto-ABNO results in the partial conversion of HMF to DFF. Increasing the amounts of keto-ABNO and $\mathrm{NaNO}_{2}$ does not lead to a continuous

Table 3 Aerobic oxidation of HMF to DFF under different amounts of keto-ABNO and $\mathrm{NaNO}_{2}$

\begin{tabular}{llllll}
\hline Entry & $\begin{array}{l}\text { Keto- } \\
\text { ABNO } \\
(\mathrm{mg})\end{array}$ & $\mathrm{NaNO}_{2}(\mathrm{mg})$ & $\begin{array}{l}\mathrm{HMF} \\
\text { conversion } \\
(\%)\end{array}$ & $\begin{array}{l}\text { DFF yield } \\
(\%)\end{array}$ & $\begin{array}{l}\text { DFF } \\
\text { selec- } \\
\text { tivity } \\
(\%)\end{array}$ \\
\hline 1 & 0 & 0 & 44.3 & $<1$ & $<1$ \\
2 & 0 & 3.4 & 69.4 & $<1$ & $<1$ \\
3 & 1 & 3.4 & 100.0 & 72.4 & 72.4 \\
4 & 2 & 3.4 & 100.0 & 81.1 & 81.1 \\
5 & 4 & 3.4 & 100.0 & 72.4 & 72.4 \\
6 & 2 & 0 & 100.0 & 32.2 & 32.2 \\
7 & 2 & 1.7 & 100.0 & 78.4 & 78.4 \\
8 & 2 & 3.4 & 100.0 & 81.1 & 81.1 \\
9 & 2 & 6.8 & 100.0 & 72.1 & 72.1 \\
\hline
\end{tabular}

Reaction conditions: HMF ( $65 \mathrm{mg}, 0.5 \mathrm{mmol})$, acetic acid (4 mL), $\mathrm{NaNO}_{2}$, keto-ABNO, $\mathrm{O}_{2}(10 \mathrm{~mL} / \mathrm{min}), 40{ }^{\circ} \mathrm{C}, 2 \mathrm{~h}$ 

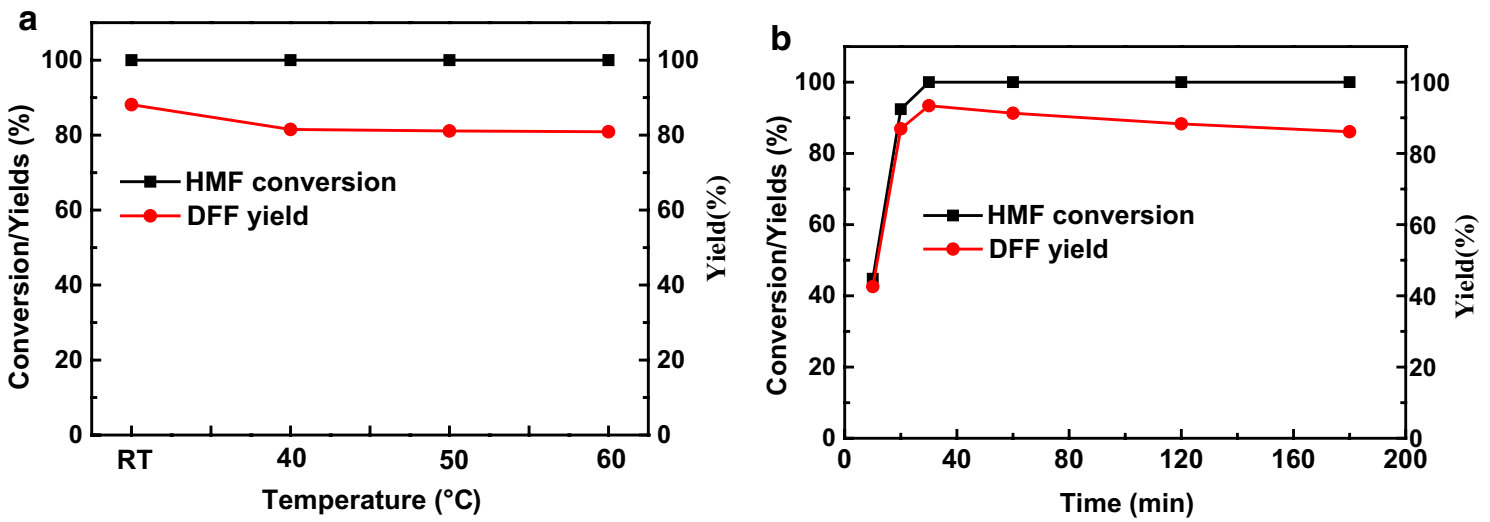

Fig. 2 Effects of a temperature, b reaction time on oxidation of HMF to DFF (if not specified, the default reaction conditions are as follows: $\mathrm{HMF}$ (65 mg, $0.5 \mathrm{mmol}), \mathrm{NaNO}_{2}(3.5 \mathrm{mg}, 0.025 \mathrm{mmol})$, keto-ABNO $(2 \mathrm{mg})$, solvent $\left.(4 \mathrm{~mL}), \mathrm{O}_{2}(10 \mathrm{~mL} / \mathrm{min}), 40{ }^{\circ} \mathrm{C}, 2 \mathrm{~h}\right)$

increase in the DFF yield. Considering the formation of other by-products (e.g., FFCA, FDCA), the optimal dosages of keto-ABNO and $\mathrm{NaNO}_{2}$ are $2 \mathrm{mg}$ and $3.4 \mathrm{mg}$, respectively. We note that the dosages of catalysts used in our catalytic system are much lower than those reported in Refs. [2, 22], while the amount of catalyst used represents a major cost in the industrial production of DFF. The high catalytic efficiency of keto-ABNO and $\mathrm{NaNO}_{2}$ makes them good candidates for the industrial-scale production of DFF.

\section{Effects of Temperature and Reaction Time on the Oxidation of HMF to DFF}

To gain a better understanding of the catalytic kinetics of the reaction, we investigated the oxidation of HMF at temperatures of 40,50 , and $60{ }^{\circ} \mathrm{C}$. The results indicate that the DFF yield decreases slightly with increasing temperature (Fig. 2a). According to the data, it is the most suitable condition at room temperature, yielding a full conversion of HMF and a DFF yield of $88.1 \%$. Moreover, we also investigated the effect of reaction time on the oxidation of HMF to DFF, the results of which are shown in Fig. 2b. Compared to results reported in the literature, our catalytic system is much faster and more efficient, with the HMF fully converted within $30 \mathrm{~min}$. In the first $10 \mathrm{~min}$, the conversion of $\mathrm{HMF}$ was very fast, which might be due to the high concentration of HMF. The highest yield of DFF was $93.4 \%$ at $30 \mathrm{~min}$. Longer reaction times resulted in a lower selectivity of DFF, mainly because of the overreaction of HMF, which leads to the further transformation of DFF into FFCA or FDCA.

\section{Possible Mechanism of Keto-ABNO Catalytic Oxidation of HMF to DFF}

Based on our experiments and previous reports [29, 30], we proposed a possible mechanism for the keto-ABNO catalytic oxidation of HMF to DFF, as shown in Scheme 2. In the catalytic reaction, we suggest that the oxidation of HMF to DFF is achieved through the coupling of multiple redox reactions. Cycle (I) involves an oxoammonium cation, which is initially oxidized from keto-ABNO, which has the ability to oxidize HMF to DFF. In this process, keto-ABNOH is continuously oxidized to oxoammonium cations with $\mathrm{NO}_{2}$, and the $\mathrm{NO}_{2}$ is considered to play the role of oxidant, having been initially produced through the deposition of $\mathrm{NaNO}_{2}$ (Scheme 2). Cycle (II) shows the transformation between $\mathrm{NO}_{2}$ and NO. The NO, which is reduced by keto-ABNOH, is oxidized into $\mathrm{NO}_{2}$ in the presence of oxygen. By the coupling of Cycles (I) and (II), a novel, coherent, and efficient aerobic oxidation system is achieved, leading to the highly selective production of DFF with a yield of $93.4 \%$ under optimal conditions.

\section{Conclusions}

In summary, we have successfully developed a highly efficient keto-ABNO catalytic system for the selective oxidation of HMF to DFF. This oxidation can occur at room temperature with $2.8 \%$ of keto-ABNO and a small amount of sodium nitrite. Under optimal reaction conditions, we achieved a full conversion of HMF and a $93.4 \%$ selectivity of DFF within $30 \mathrm{~min}$. With the advantages of a high reaction rate, low catalyst dosage, and mild reaction conditions, the keto-ABNO catalytic system shows great promise for the industrial-scale production of DFF in achieving the cost-effective conversion of biomass into high-value chemicals.

Acknowledgements This study was supported by the Natural Science Foundation of Tianjin, China (No. 16JCYBJC19600), Natural Science Foundation of China (No. 21621004), Beiyang Young Scholar of Tianjin University (2012), and the State Key Laboratory of Chemical Engineering (No. SKL-ChE-08B01). 
Open Access This article is distributed under the terms of the Creative Commons Attribution 4.0 International License (http://creativeco mmons.org/licenses/by/4.0/), which permits unrestricted use, distribution, and reproduction in any medium, provided you give appropriate credit to the original author(s) and the source, provide a link to the Creative Commons license, and indicate if changes were made.

\section{References}

1. Chheda JN, Huber GW, Dumesic JA (2007) Liquid-phase catalytic processing of biomass-derived oxygenated hydrocarbons to fuels and chemicals. Angew Chem Int Edit 46(38):7164-7183

2. Antonyraj CA, Jeong J, Kim B et al (2013) Selective oxidation of HMF to DFF using Ru/ $\gamma$-alumina catalyst in moderate boiling solvents toward industrial production. J Ind Eng Chem 19(3):1056-1059

3. Ventura M, Aresta M, Dibenedetto A (2016) Selective aerobic oxidation of 5- (hydroxymethyl)furfural to 5-formyl-2-furancarboxylic acid in water. ChemSusChem 9(10):1096-1100

4. Casanova O, Iborra S, Corma A (2009) Biomass into chemicals: aerobic oxidation of 5-hydroxymethyl-2-furfural into 2,5-furandicarboxylic acid with gold nanoparticle catalysts. ChemSusChem 2(12):1138-1144

5. Deng J, Song HJ, Cui MS et al (2014) Aerobic oxidation of hydroxymethylfurfural and furfural by using heterogeneous $\mathrm{Co}_{x} \mathrm{O}_{y}-\mathrm{N} @ \mathrm{C}$ catalysts. ChemSusChem 7(12):3334-3340

6. Sun Y, Ma H, Jia X et al (2016) A high-performance base-metal approach for the oxidative esterification of 5-hydroxymethylfurfural. ChemCatChem 8(18):2907-2911

7. Thananatthanachon T, Rauchfuss TB (2010) Efficient production of the liquid fuel 2,5-dimethylfuran from fructose using formic acid as a reagent. Angew Chem Int Edit 49(37):6616-6618

8. Zu Y, Yang P, Wang J et al (2014) Efficient production of the liquid fuel 2,5-dimethylfuran from 5-hydroxymethylfurfural over $\mathrm{Ru} / \mathrm{Co}_{3} \mathrm{O}_{4}$ catalyst. Appl Catal B-Environ 146(3):244-248

9. Poeta MD, Schell WA, Dykstra CC et al (1998) Structure-In vitro activity relationships of pentamidine analogues and dication-substituted bis-benzimidazoles as new antifungal agents. Antimicrob Agents Chemother 42(10):2495-2502

10. Hopkins KT, Wilson WD, Bender BC et al (1999) Extended aromatic furan amidino derivatives as anti-pneumocystis carinii agents. J Med Chem 30(11):3872-3878

11. Moreau C, Belgacem MN, Gandini A (2004) Recent catalytic advances in the chemistry of substituted furans from carbohydrates and in the ensuing polymers. Top Catal 35(31):11-30

12. Richter DT, Lash TD (1999) Oxidation with dilute aqueous ferric chloride solutions greatly improves yields in the ' $4+1$ ' synthesis of sapphyrins. Tetrahedron Lett 40(37):6735-6738

13. Amarasekara AS, Green D, Williams LTD (2009) Renewable resources based polymers: synthesis and characterization of 2,5-diformylfuran-urea resin. Eur Polym J 45(2):595-598

14. Ma J, Du Z, Xu J et al (2011) Efficient aerobic oxidation of 5-hydroxymethylfurfural to 2,5-diformylfuran, and synthesis of a fluorescent material. ChemSusChem 4(1):51-54

15. Xu F, Zhang Z (2015) Polyaniline-grafted $\mathrm{VO}(\text { acac })_{2}$ : an effective catalyst for the synthesis of 2,5-diformylfuran from 5-hydroxymethylfurfural and fructose. ChemCatChem 7(9):1470-1477

16. Yang Z, Qi W, Su R et al (2017) 3D flower-like micro/nano CeMo composite oxides as effective bifunctional catalysts for onepot conversion of fructose to 2,5-diformylfuran. ACS Sustain Chem Eng 5(5):4179-4187

17. Le NT, Lakshmanan P, Cho K et al (2013) Selective oxidation of 5-hydroxymethyl-2-furfural into 2,5-diformylfuran over $\mathrm{VO}^{2+}$ and $\mathrm{Cu}^{2+}$ ions immobilized on sulfonated carbon catalysts. Appl Catal A-Gen 464-465(16):305-312

18. Liao L, Liu Y, Li Z et al (2016) Catalytic aerobic oxidation of 5-hydroxymethylfurfural into 2,5-diformylfuran over $\mathrm{VO}^{2+}$ and $\mathrm{Cu}^{2+}$ immobilized on amino-functionalized core-shell magnetic $\mathrm{Fe}_{3} \mathrm{O}_{4} @ \mathrm{SiO}_{2}$. RSC Adv 6(97):94976-94988

19. Fang R, Luque R, Li Y (2016) Selective aerobic oxidation of biomass-derived HMF to 2,5-diformylfuran using a MOFderived magnetic hollow $\mathrm{Fe}-\mathrm{Co}$ nanocatalyst. Green Chem 18(10):3152-3157

20. Wang Y, Liu B, Huang K et al (2016) Aerobic oxidation of biomass-derived 5-(hydroxymethyl)furfural into 2,5-diformylfuran catalyzed by the trimetallic mixed oxide ( $\mathrm{Co}-\mathrm{Ce}-\mathrm{Ru})$. Ind Eng Chem Res 53(4):1313-1319

21. Liu B, Zhang Z, Lv K et al (2014) Efficient aerobic oxidation of biomass-derived 5-hydroxymethylfurfural to 2,5-diformylfuran catalyzed by magnetic nanoparticle supported manganese oxide. Appl Catal A-Gen 472(3):64-71

22. Nie J, Xie J, Liu H (2013) Activated carbon-supported ruthenium as an efficient catalyst for selective aerobic oxidation of 5-hydroxymethylfurfural to 2,5-diformylfuran. Chin J Catal 34(5):871-875

23. Wang F, Jiang L, Wang J et al (2016) Catalytic conversion of fructose and 5-hydroxymethylfurfural into 2,5-diformylfuran over SBA-15 supported ruthenium catalyst. Energy Fuel 30(7):5885-5892

24. Fang C, Dai JJ, Xu HJ et al (2015) Iron-catalyzed selective oxidation of 5-hydroxylmethylfurfural in air: a facile synthesis of 2,5-diformylfuran at room temperature. Chin Chem Lett 26(10):1265-1268

25. Mittal N, Nisola GM, Malihan LB et al (2014) Metal-free mild oxidation of 5-hydroxymethylfurfural to 2,5-diformylfuran. Korean J Chem Eng 31(8):1362-1367

26. Lauber MB, Stahl SS (2013) Efficient aerobic oxidation of secondary alcohols at ambient temperature with an $\mathrm{ABNO} / \mathrm{NO}_{x}$ catalyst system. ACS Catal 3(11):2612-2616

27. Sever RR, Root TW (2003) DFT study of solvent coordination effects on titanium-based epoxidation catalysts. Part two: reactivity of titanium hydroperoxo complexes in ethylene epoxidation. $\mathrm{J}$ Phys Chem B 107(17):4090-4099

28. Ma S, Liu J, Li S et al (2011) Development of a general and practical iron nitrate/TEMPO-catalyzed aerobic oxidation of alcohols to aldehydes/ketones: catalysis with table salt. Adv Synth Catal 353(6):1005-1017

29. Dijksman A, Arends IW, Sheldon RA (2003) Cu(II)-nitroxyl radicals as catalytic galactose oxidase mimics. Org Biomol Chem 1(18):3232-3237

30. Liu R, Liang X, Dong C et al (2004) Transition-metal-free: a highly efficient catalytic aerobic alcohol oxidation process. J Am Chem Soc 35(32):4112-4113 